\title{
Going Digital in Design Education: Restructuring the Emotional Bonds in the Online Studio
}

\author{
Yasemin Burcu Baloglu \\ MEF University, Faculty of Arts, Design, and Architecture (FADA), Istanbul, Turkey \\ Ahmet Sezgin \\ MEF University, Faculty of Arts, Design, and Architecture (FADA), Istanbul, Turkey
}

Received: April 28th 2021, Revised: May 26th 2021, Accepted: June 7th 2021.

Refer: Baloglu, Y.B., Sezgin, A., (2021), Going Digital in Design Education: Restructuring the Emotional Bonds in the Online Studio, Journal of Design Studio, V.3, N.1, pp 49-58,

Y.B. Baloglu ORCID: 0000-0002-6391-1894, A. Sezgin ORCID: 0000-0003-3959-3803

DOI: $10.46474 /$ jds.929594 https://doi.org/10.46474/jds.929594

\begin{abstract}
Higher education has experienced momentous changes in 2020-21 due to the COVID-19 restrictions disrupting face-to-face education. An immediate shift to online education that draws on diverse digital platforms and interfaces took place worldwide. This study aims to present insights into this transition process from the perspective of place attachment and sense of belonging with a focus on the design studio, and it specifically looks at the transition to online education carried out by the Faculty of Arts, Design, and Architecture (FADA) at MEF University. The study draws on semi-structured interviews conducted with students from the faculty. Responses from the students indicate that they have felt the effects of the transition process in social relationships, time-space routines, safe space, and changes in their perceptions of personal space. Recent research has demonstrated that sense of belonging and place attachment in educational environments positively affect students' academic performance. The data obtained through this study reiterates the significance of these bonds in the design studio context. The discussion introduces a fresh insight into exploring these critical concepts by focusing on the now burgeoning field of online design education.
\end{abstract}

Keywords: Digital learning environments, design education, design studio, online education, place attachment, sense of belonging

\section{Introduction}

Education has been one of the most significantly affected fields by the pandemic during 2020. Within the scope of the measures taken, face-to-face education processes were suspended in schools all over the world, and online education began to be applied widely through digital platforms. Architecture and design schools have been considerably affected by the relocation process due to the unique nature of the pedagogical approaches of their curriculums. The transition to online education was remarkably sudden and in all facets of design education, including but not confined to design studio, theory courses, and visual communication. All of the courses needed to be immediately adapted to digital platforms.

The immediate transition of education to digital platforms, on the other hand, raised some questions about students' relationships with educational institutions and the field of design. This study aims to explore this transition process from a perspective of "belongingness" and "attachment" to the studio environment, based on the acceptance that the design studio is one of the development areas of spatial belonging. The online education experience at MEF University Faculty of Art, Design, and 


\section{Journal of \\ Design Studio}

v:3 n:1 July 2021

Architecture (FADA) is examined as a case study.

As indicated in research findings [France, et al. 2010; Freeman, 2007], the design studio environment provides a fertile ground for building diverse and multi-level social relationships. Thus, it has a significant potential to support academic achievement by enhancing spatial belonging and place attachment. Design studios reflect a common culture that transcends the boundaries of different design traditions. In the FADA studio, which is the subject of the study, learning processes are intertwined with various social environments in the studio, and the place is used as a collective design area besides accommodating the project courses. The studio encourages students' learning experiences by providing space for different learning modes such as workshops, designbuild experiments, and seminar programs.

Like in many studio-oriented design schools, the design studio lies at the core of the education at FADA. The curriculum revolves around the studio work, and the culture of the faculty draws considerably on the character of its open-plan studio environment named Hangar (Fig.1). Students of both programs come together in this area for design studios, some of the theoretical courses, hands-on practices, collaborative productions, informal meetings, seminars, and various studio activities (Fig.2). The studio constitutes a vibrant environment that is twentyfour hours open and accessible throughout the school year. The open layout plan and mixed profile of students enable students to follow each other's design works through casual talks and socializing as well as discussion forums, exhibitions, regularly held reviews, and design juries. All the students are provided with private desks and storage cabinets for their tools and other belongings, which enables and leads to highly personalized individual work spots in the open plan layout of the studio. As a result, the design studio corresponds to an accessible, interactive, and intensive learning environment for the students where they spend a considerable amount of time and even choose to stay in during some nights to work on their design projects during some periods.

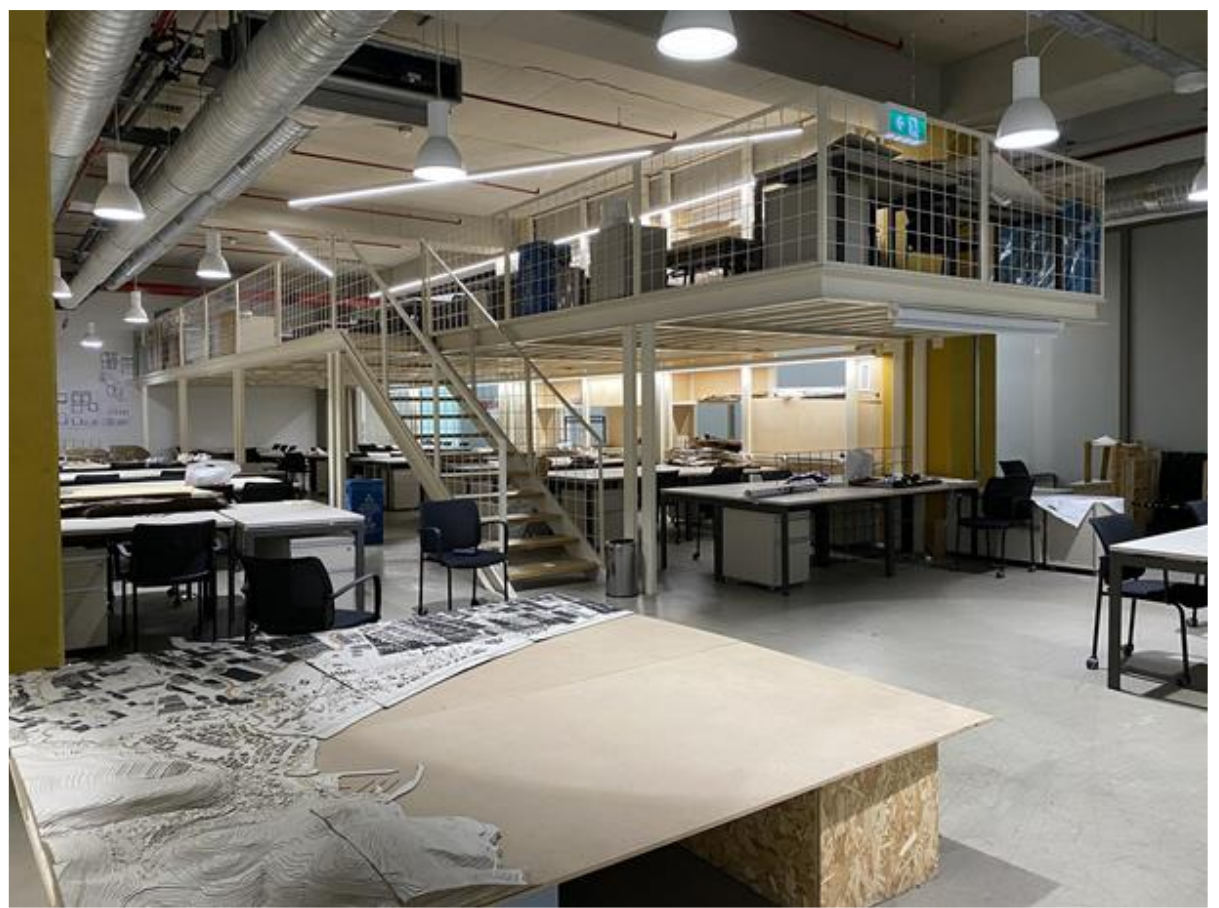

Figure 1: View from Hangar, the design studio used by

Faculty of Arts, Design and Architecture (FADA) at MEF University

(Source: Burcu Baloglu Year: 2020) 


\section{Journal of \\ Design Studio}

$\mathrm{v}: 3 \mathrm{n}: 1$ July 2021

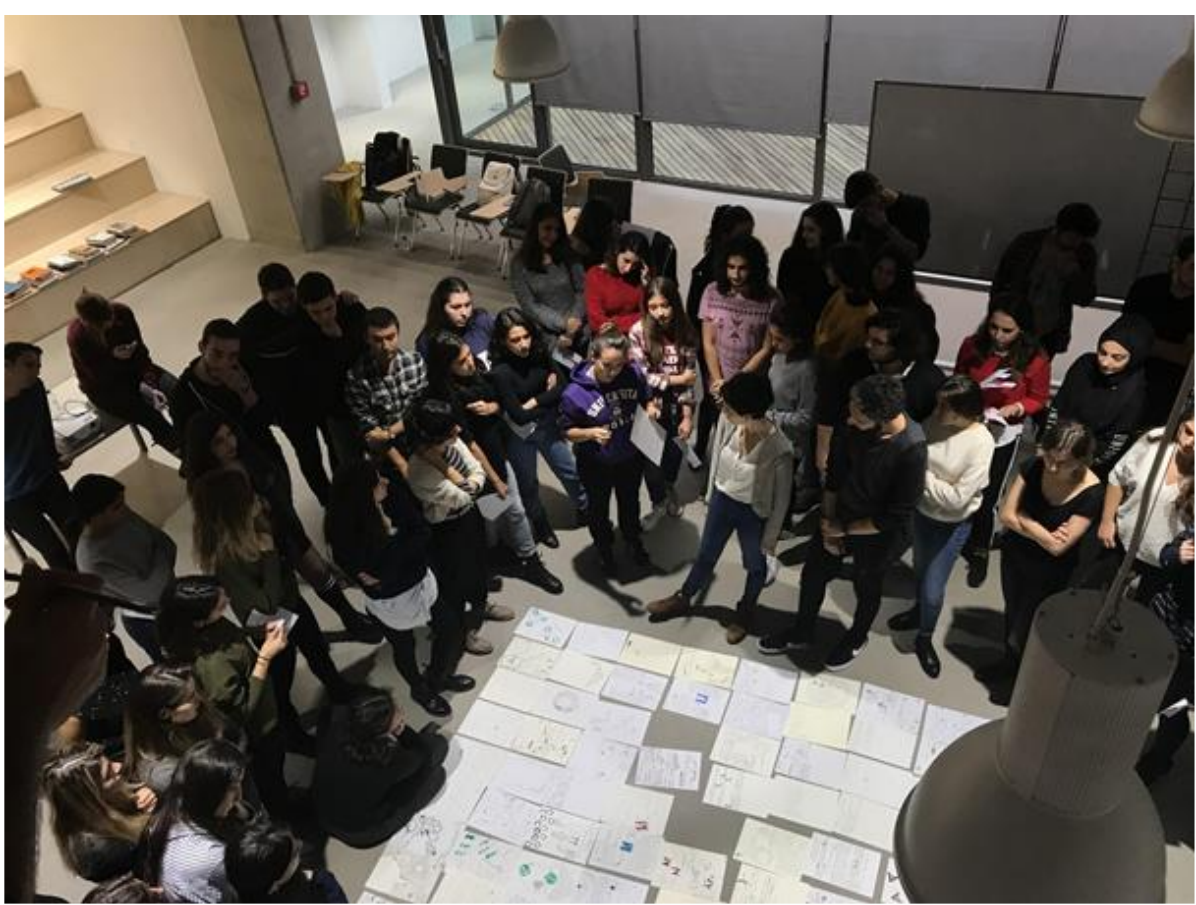

Figure 2: Students discussing on sketches they

have produced during a visual communication course session

(Source: Burcu Baloglu Year: 2020)

\section{Place Attachment, Sense of Belonging and Learning Environments}

The concepts of place attachment and sense of belonging have been subjects of studies in different fields such as environmental psychology, sociology, and architecture. Although there is a diversity in the definitions of place attachment in literature, the explanations of the term revolve around the affective links, emotional bonds, and interactions between people and places. When individuals stay in a place for a long time, they tend to develop a sense of belonging to that place. Research demonstrates that attachment has often been approached as a multidimensional concept that includes person, place, and psychological process dimensions. The psychological processes can be formed as affective, behavioral, and cognitive bonds between individuals and their meaningful environments [Chow and Healey, 2008; Hidalgo and Hernandez, 2001; Scannell and Gifford, 2010]. These emotional links are often associated with having positive feelings about a place [Lewicka, 2010]. The affective dimension of place attachment is related to the emotional connection that a person has toward a place that includes liking and feeling happy in that environment [Scannell and Gifford, 2010] and having a sense of belonging or connectedness [Gustafson, 2009]. Studies indicate that people tend to develop affective bonds with places that permit control, foster creativity, and provide privacy, safety, security, and serenity [Altman and Low, 1992: Chow and Healey, 2008]. Another dimension of attachment occurs in the behavioral level, in which individuals express their attachment through staying in a particular place and proximity-maintaining behaviors [Scannell and Gifford, 2010]. Accordingly, they desire to remain close to a place for long periods and relocate to similar places. The third aspect of attachment, the cognitive dimension, includes the memories and the meaning associated with the place [Scannell and Gifford, 2010].

Much of the relevant literature about place attachment focuses on understanding the bonds with residence and the immediate communities such as home, neighborhoods, or countries. However, there is also a growing number of recent studies searching for the experiences in other places and their meanings for people. 


\section{Journal of \\ Design Studio}

v:3 n:1 July 2021

Lewicka [2011] mentions that the critical requirement to investigate an environment from a place attachment perspective is the place's being meaningful for an individual or a group of people. Accordingly, the concept of attachment can be applied to different types of environments varying in terms of type and scale, such as working environments, football grounds, sacred sites, or even virtual and imaginative spaces [Lewicka, 2010]. Recent studies show that there has also been a growing interest in place attachment and its implications in educational settings. The university environments need to be addressed from this viewpoint, considering that students spend at least four years of their lives in these spaces.

Place attachment studies related to learning environments indicate that attachment is a significant component of positive academic motivations and outcomes [Bergin and Bergin, 2009; Freeman, Anderman and Jensen, 2007; $\mathrm{Li}, 2012$ ], and sense of belonging is an essential concept in educational settings which contributes to the motivation of students and engages them in learning [ $\mathrm{Li}$, et al. 2013; Osterman, 2000]. Moreover, environments that enhance positive emotional states are expected to facilitate learning and the development of place attachment [Graetz, 2006]. Osterman [2000] discusses that students experience school as a community that they need to feel belonged, related, or as a part of the group, and asserts that the social context in the educational setting plays a significant role in developing these bonds. There are also studies adding support to the argument that having more social contacts with people in the university may relate to more substantial development of attachment to the school [Li, et al. 2013]. There are also burgeoning sub-field of studies that address the place attachment concept in digital or virtual environments. Arora and Khazanchi [2014], for example, touch upon the discussion from a social perspective. The authors [Arora and Khazanchi, 2014] suggest that in virtual learning environments, collaborative works that involve interactions among a group of students who manipulate or work on the same task together, the social sub-component of place attachment gets improved as it also happens in physical environments. It can be inferred from the sources mentioned related to the subject that it is possible to construct multi-layered forms of sense of belonging to the place in educational environments such as design studios that allow the establishment of various social relationships. As a physical, cultural, and social place, the design studio constitutes an area in which complex interactions of place attachment with the learning processes can be explored.

\section{Capturing students' insights about the transitional process from the studio to the digital platform}

In March 2020, the preventive measures to slow the spread of the pandemic brought about an interruption of face-to-face education for a long time in schools and higher education institutions. An immediate adjustment period to the new situation started, and educational practices were moved to online learning platforms in most universities, including MEF University. Studio sessions were conducted online throughout the following year due to the obligatory shift to adapt to the "new normal" situation. The loss of the physical environment has come up with its constraints; on the other hand, this change led to revealing potentials in alternative ways of sharing knowledge. Moreover, the situation created an interest in searching for how the students internalize this loss and discuss how some intangible factors that affect studio experience, including the sense of belonging and place attachment, were redefined in the new digital environment.

A qualitative study was conducted to explore the students' thoughts about the transition process they have experienced in FADA. The inferences were drawn on semi-structured interviews conducted in Turkish with each of the twenty third-year and fourth-year design students from the faculty. The students who contributed to the interviews have spent at least two years in the design studio, and they were involved in diverse kinds of activities performed in this environment. Interviewees participated voluntarily after responding to an open call in an email from the authors to the third and fourth year students at the faculty. Interviews took place in February and March 


\section{Journal of \\ Design Studio}

v:3 n:1 July 2021

2021 at Zoom and through emails when necessary.

Five open-ended questions in the interviews explored students' depictions of the design studio, how they socially relate themselves to the physical environment, and how their working routines were affected during the relocation process. When necessary, follow up questions were asked to clarify the wordings. The overall interview aimed to dive into the narrative descriptions to reveal intertwining attachments with the studio setting and pinpoint emotional bonds. The study concentrated on certain themes that were deduced from recurrent terms and concepts stated by the students during the interviews. Changes in social relationships and working habits and thoughts about privacy in the digital environment were these highlighted themes in students' responses, directly or indirectly affecting spatial belonging and place attachment dynamics.

\section{Place attachment by social dynamics in design studio}

The transition process from face-to-face to screen-to-screen learning in the digital environment has also created challenges related to social relations with peers and instructors. Students experienced the multi-faceted change in these social dynamics and the outcomes of the absence of the physical space design immediately with the launch of online education. The absence of an interactive environment that supports the informal learning process after course hours have to be substituted in an online learning environment. Students' descriptions of Hangar during the interviews showed that in the conventional situation they perceive the studio environment as a supporting, warm, accessible, inspiring, and comfortable "space for living," enhancing collaborative design works, gatherings for lectures, and individual studies. The positive attributes that students chose to talk about while defining the space such as warmth, respectful interactions between instructor and students, cooperative interactions among students can be associated with the items approached as indicators related to school attachment [Freeman, 2007]. Responses of FADA students to the questions of "How would you define Hangar? and What does Hangar mean to you as a space for studying and socialization?" highlights the significance of social interaction for them.

It is not just a studio space for studying, but it is a space for living together for both architecture and interior design students, where they can spend time with each other and the instructors (4th-year student)

Hangar has a warm and friendly atmosphere. It is a very comfortable working environment where you can study without distractions. (3rd-year student)

I think Hangar is inspiring as a studio space, and I believe it provides an area where we can socially cooperate and support each other's motivation to work. (4th-year student)

Responses frequently mention the phrases of "togetherness" and "being together" that are significant components of sense of belonging and attachment. In these terms, it is possible to talk about a unique, shared culture that has been developed in the studio. All these responses reveal the interaction among the students and studio instructors and highlight the significance of the social culture at the design studio from the students' point of view.

In general, I see Hangar as a field of cooperation and socialization. More specifically, I can say that it is a space where we can exchange ideas and find solutions to our problems. (3rd-year student)

Hangar is a well-equipped environment where we help each other with our professors and our friends regardless of our level of class. We can easily reach the instructors without looking for them everywhere. Its open plan allows us to see the works of other students and share opinions. We don't feel confined or surrounded by walls in this space. It is an 


\section{Journal of \\ Design Studio}

v:3 n:1 July 2021

interactive and warm environment where we can spend our time during the whole night by studying and drinking coffee with our classmates. (3rd-year student).

In Hangar we can quickly fulfill our needs, easily reach the instructors, and get motivated to study. It is a highly social and encouraging environment where we can spend time with our friends after the formal course hours and work together. (4th-year student)

Some of the students emphasized Hangar's being a special place that is only open to FADA students' access as a characterizing attribute. This viewpoint can also be interpreted as related to their social identification with a particular group, in this case, faculty of design students and instructors to whom they develop a kind of belonging. This is in fact a highly significant outcome of learning in the physical studio. As Yanar [2000] underlines, students learn not only how to design but also how to become a member of its professional community. The concept of "social space" in FADA students' responses includes studio, goes beyond it, and demonstrates students' recognition of the topic.

Hangar is a space for living that is only accessible to the students of FADA. I think the Hangar intensifies our learning experience because we have the opportunity to spend 24 hours in an open space with all the other students. The openplan actually provides us many options. We have the chance to follow and observe other students' works very easily. Moreover, we always have the right to access the lectures for other studio groups when they invite a guest lecturer. So, for me, Hangar is more like a social area which also accommodates the design studio. (4thyear student)

At the faculty this study focused on, the transition to online education was managed without a major shortfall in terms of technological infrastructure. Nonetheless, students lost access to the physical design studio and were confined to their private living environments. Subsequently, intangible social aspects that are intertwined with the studio's physical environment and created by various factors such as social interaction and informal gatherings were lost. As recognized by the faculty, these social attributes of the design studio significantly affect the academic motivation. Alternative digital activities and online meeting rooms for informal or education related communication were formed to compensate for missing communication and interaction traits.

In the interviews, questions of "After the transition to online education, Has your way of working for the design studio changed? If yes, What kind of change has taken place?" were asked to the students. Comments by the students demonstrate that despite the opportunities of online social interaction, it is challenging to replicate the atmosphere of the physical design studio. One of the foremost challenges cited by the student is the emotional tension that is caused by the curtailment of the daily interaction with peers and being detached from the routines of the design studio while working alone at home.

My working environment at home is not like at school, making me feel involuntary to work. It is not easy to chat and share information about the project with my friends or ask each other questions during the online studio. So, I often get stuck in even a simple problem just because I feel confused about it. Also, I think one of the most important differences between online and school education is that it is less disciplined, and I use my time inefficiently when I work alone at home. (4th-year student)

Some students even commented that they have tried to meet with their friends in the partially accessible, almost totally empty design studio, and attend their online lessons together. They mentioned that they are much more motivated for studio sessions when they are together with their friends in the atmosphere of the design studio. 


\section{Journal of \\ Design Studio}

v:3 n:1 July 2021

[...] I just can't believe I've missed this place so much! Before the shutdown, I was complaining about spending so much time sitting on these chairs. After working at home alone for a long time, I now understand that the studio creates a social, collaborative, and creative environment for us. And for now, it is even better because only a few people are coming to Hangar to study, so this huge space all belongs to us! (3rd-year student)

Comments by the students emphasize the sense of belonging and place attachment formed by the social interaction in the design studio. It demonstrates that the studio environment has considerable significance for their academic motivation. Students have the opportunity to position themselves in relation to their peers, their achievements in their studies, and professional life while becoming part of the interactive network of the design studio. However, interactions and spontaneous encounters are limited in the online environment.

\section{Privacy and safe space within online design studio}

FADA students considered the role of the design studio as a safe space for social interaction and as an equalizer of social and economic inequalities. In the interviews, they recognized the negotiation of privacy dimensions and the culture of social interaction in the physical studio space. The students' comments may be seen both from the lenses of social relations and privacy dimensions. During the online courses, sharing their desktop screens which allowed all their friends and instructors to glimpse into their home and rooms, indeed became an invasive situation for some students. Besides the privacy dimension, the physical environment's ability to impose equality in various terms, to remove the barriers in studentinstructor relationships, and to provide a space where students feel "safe" for being able to be an equal part of the community regardless of their backgrounds seems to be a significant attribute emphasized in the comments.
[...] students can create their own private spaces within the frame of respect to peers. Unlike in other parts of the university, there is opportunity to communicate and cooperate regardless of age, class, and culture thanks to the flexible environment. In my opinion, sharing the same space creates the environment where everyone feels equal. This enables communication and reaching out to people.

Students' emphasis on the "sharp boundaries" and their exclusion of the design studio from this statement reflected their awareness about the studio as an inclusive space. The commentary by FADA students about the role of the design studio underlines the design studio as an equalizer among "students from various years of study," "students and instructors," and students from different socio-economic backgrounds. Chow and Healey [2008] assert that the design studio provides a peaceful personal working space free from dysfunctional social environments and reliable technical infrastructure for students from a disadvantaged economic status. Privacy, safety, and serenity are the qualities provided by the design studio that form effective bonds towards place attachment [Chow and Healey, 2008]. In this context, McLaren also sees the design studio as a "safe space," providing access for all students to a certain level of infrastructure and, therefore, hiding the inequities (URL-1). As safe spaces, design studios and their threshold spaces accommodate diverse contacts and interactions, many of which are not directly accessible to disadvantaged students. In Istanbul, one of the largest metropolises in the developing world, students from low-income families face the bitter fact that the city has limited public spaces that are part of design culture and accessible without economic power. Design studio empowers the students with the attachment to a design school that provides formal and informal opportunities to be part of the network. Transition to online education disrupts this multifaceted safe space and undermines the emotional bonds nurturing the students' feelings of safety and security. In the absence of such a safe space at design studios, digital technology can hardly act as an "equalizing force," as many 


\section{Journal of \\ Design Studio}

v:3 n:1 July 2021

instructors have already noted [Corcoran, 2020]. FADA students' responses revealed the studio's role as a balancing social environment that seems challenging to form on online platforms.

\section{Changes in Time-Space Routines}

David Seamon [2020] suggests that daily activities create routines within the rhythm of life and connections with place attachments. The everyday activities collectively form an 'existential insideness' that corresponds to belonging within the rhythm of life in place. These routines constitute regularity to create new patterns and emotional bonds [Seamon, 2020]. The strength of emotional bonds with places is strongly related to the residence time as the time-space routines develop gradually in time [Lewicka, 2011]. In design studios, arrivals, critics, juries, and rituals of individual study are the diverse activities composing timespace routines. The design studio becomes a constantly alive space by these daily, weekly, and termly patterns. The constant use of space and its distinctive routines reflecting the progress of the design project is markedly different from being in classrooms with sharp boundaries of occupation time. Students at MEF reflected this as they underlined the loss of the routines of work they had before at the design studio. They rightly noted that work settings at home or in public spaces during online education lack such a stimulating pattern.

Online education was challenging at first, and of course, my work routine and form had changed. I had to concentrate twice as much as I do in school and work a little more than my regular and planned work. It was more difficult to understand and express ideas because of the lack of the physical environment. Therefore, we had to come a little more prepared than we usually do before the lessons.

As the students noticed, they found themselves caught in between the clashing routine of the residence and the routine of the design process.
I think the routine of the lessons changed. The environments we are in have a certain routine. For example, Hangar has a particular course schedule, but we were creating our routine within this program. When we switched to online education, we have moved into an environment that already has its particular routine. Adaptation to the new situation changed the way we study and our routine in terms of working hours, study settings, efficiency, and many other things. Whether the change is good or bad depends on the new environment in which we continue to work.

Therefore, students' experience of the change was not only by the detachment from the physical environment but also loss of the timespace routine created there. Students' positive appraisal of the online education rested on their ability to synchronize the routines of life at the residence and the routine of the design process inherited from Hangar. As underlined by students' responses, a positive development in the students' daily routine was the saved time spent for commuting. In a metropolis without an efficient public transportation system, online education also meant the possibility of avoiding lengthy and crowded commutes between the university and residence. Students cited saving the time spent commuting to the university as a positive factor for their wellbeing and concentration on their education.

[...] The time I spent working has increased since the time I spend on commuting has disappeared. I have managed to study more comfortably for more extended periods. Yes, I have a problem with concentration at home. But since I don't have to commute to school, I feel less tired, and I can spare more time for my lessons. With online education, the working hours I spared for the project course have increased, and I began to use the course hours more efficiently.

Recalling Seamon's [2020] remarks about the relationship between recurring daily routines and place attachment, students' perception of 


\section{Journal of \\ Design Studio}

v:3 n:1 July 2021

the design studio can be approached as an essential part of their daily rhythms. It is the capacity to adapt to the time-space routines that determine the nature of the students' adoption of the new pattern as positive or negative.

\section{Conclusive remarks}

Educational institutions are responsible for enriching the learning processes and providing institutional support for the students during these processes. The sudden and inevitable transition to online education platforms has created opportunities and challenges alike. The change provided encounters with new educational tools and enabled quick interaction and communication in these online tools. Nevertheless, maintaining studio culture and interaction among students and professors emerged as challenges, despite replicating many aspects of the design studio by online education tools. Furthermore, there is a fair demand for safe space, place attachment, and equal opportunity in online education.

Online education should venture beyond the straightforward adaptation of online tools in design education, considering the positive role of place attachment in academic achievements. Design schools found themselves in a position of substituting the social relationships and collective identity in the design studio with the online education tools. The absence of the physical design studio exposed the social and economic inequalities among the students. Responses of the FADA students in the interviews demonstrate that the inequalities among the students should be a significant concern to be able to provide inclusive online education. The changes in the time-space routines were one of the major outcomes of the loss of the physical design studio. Students are composed of diverse individuals with varying capacities of neatly overlapping design studio routines and the routines of the living spaces together. For some of the students, the living environments do not necessarily provide them the freedom of establishing individual spaces and routines. Design education entails a vibrant tradition of collective work revolving around the physical design studio. Online design studios have the potential to replicate this by interfaces that can host visuals of group works in a synchronized and informal manner. Recreating the design studio in online education can be plausible only by taking the diverse capacities of the individuals into account and forming student-oriented strategies.

\section{References:}

Altman, I. \& Low, S. M. (1992). Place attachment. In Place attachment (pp. 1-12). Springer, Boston, MA.

Arora, V., \& Khazanchi, D. (2014). Sense of Place in Virtual Learning Environments. In MWAIS Conference, Iowa State University, USA. http://aisel.aisnet.org/mwais2014/8

Bergin, C., \& Bergin, D. (2009). Attachment in the classroom. Educational Psychology Review, 21(2), 141-170. https://doi.org/10.1007/s10648-009-9104-0

Chow, K., \& Healey, M. (2008). Place attachment and place identity: First-year undergraduates making the transition from home to university. Journal of Environmental Psychology, 28(4), 362-372.

https://doi.org/10.1016/j.jenvp.2008.02.011

Corcoran, H. (2020). Architecture Schools Adapt to an Uncertain Future. Architectural Record. Retrieved 14 October 2020, from https://www.architecturalrecord.com/articles/1 4569-architecture-schools-adapt-to-anuncertain-future

France, M. K., Finney, S. J., \& Swerdzewski, P. (2010). Students' group and member attachment to their university: A construct validity study of the University Attachment Scale. Educational and Psychological Measurement, 70(3), 440-458.

https://doi.org/10.1177/0013164409344510

Freeman, T. M., Anderman, L. H., \& Jensen, J. M. (2007). Sense of belonging in college freshmen at the classroom and campus levels. The Journal of Experimental Education, 75(3), 203-220.

https://doi.org/10.3200/JEXE.75.3.203-220 


\section{Journal of \\ Design Studio \\ v:3 n:1 July 2021}

Graetz, K. A. (2006). The psychology of learning environments. Educause Review, 41(6), 60-75.

https://www.educause.edu/research-andpublications/books/learning-spaces/chapter-6psychology-learning-environments

Gustafson, P. (2009). Mobility and territorial belonging. Environment and Behavior, 41(4), 490-508.

https://doi.org/10.1177/0013916508314478

Hidalgo, M. C., \& Hernandez, B. (2001). Place attachment: Conceptual and empirical questions. Journal of Environmental Psychology, 21(3), 273-281.

https://doi.org/10.1006/jevp.2001.0221

Lewicka, M. (2010). What makes neighborhood different from home and city? Effects of place scale on place attachment. Journal of Environmental Psychology, 30(1), 35-51. https://doi.org/10.1016/j.jenvp.2009.05.004

Lewicka, M. (2011). Place attachment: How far have we come in the last 40 years? Journal of Environmental Psychology, 31(3), 207-230. https://doi.org/10.1016/j.jenvp.2010.10.001

Li, M., Frieze, I. H., Nokes-Malach, T. J., \& Cheong, J. (2013). Do friends always help your studies? Mediating processes between social relations and academic motivation. Social Psychology of Education, 16(1), 129-149. https://doi.org/10.1007/s11218-012-9203-5

Li, M. Y. (2012). Place attachment in university students: social antecedents and academic motivations (Doctoral dissertation, University of Pittsburgh).

http://d-scholarship.pitt.edu/id/eprint/6179

Osterman, K. F. (2000). Students' need for belonging in the school community. Review of Educational Research, 70(3), 323-367. https://doi.org/10.3102/00346543070003323
Scannell, L., \& Gifford, R. (2010). Defining place attachment: A tripartite organizing framework. Journal of Environmental Psychology, 30(1), 1-10.

https://doi.org/10.1016/j.jenvp.2009.09.006

Seamon, D. (2020). Place attachment and phenomenology. Manzo, L. C., \& DevineWright, P. (Ed.). Place attachment: Advances in theory, methods and applications. Routledge, 29-44.

URL-1, Archinect. (2020). Retrieved 11,12, 2020, from

https://archinect.com/features/article/15019536 9/architecture-deans-on-how-covid-19-willimpact-architecture-education

Yanar, A. (2000). Knowledge, skills and indoctrination in studio pedagogy. Salama, A.M. and Wilkinson, N. (Ed.), Design studio pedagogy: Horizons for the future, 63- 74. 